\title{
Hubungan Penggunaan Tas Sekolah dengan Keluhan Nyeri Punggung pada Siswa di SMP Negeri 106 Jakarta
}

\section{Relationship Between Using School Bags with Back Pain Complaints to Students at SMP Negeri 106 Jakarta}

\author{
Erna Sariana $^{(1)}$, Ari Sudarsono ${ }^{(1)}$ \\ ${ }^{(1)}$ Poltekkes Kemenkes Jakarta III, Jakarta, Indonesia \\ Korespondensi Penulis : Erna Sariana \\ Poltekkes Kemenkes Jakarta III \\ Email : ernasariana.es@gmail.com
}

\begin{abstract}
ABSTRAK
Jam pelajaran sekolah dan ekstrakurikuler siswa, mempengaruhi beban tas yang dibawa sehingga timbul keluhan nyeri punggung siswa. Batas beban tas punggung yang diperbolehkan adalah $10-15 \%$ berat badan. Hal ini membuat peneliti tertarik meneliti hubungan penggunaan tas sekolah dengan keluhan nyeri punggung pada siswa di SMP Negeri 106 Jakarta tahun 2019. Jenis penelitian deskriptif dengan desain cross sectional. Sampel sebanyak 305 orang siswa SMP Negeri 106 Jakarta, dipilih dengan proporsional random sampling. Penelitian ini dilakukan pada bulan April - September 2019. Pengumpulan data menggunakan kuesioner, penimbangan berat badan dan berat tas. Analisis data dengan univariat, bivariat (uji Kai Kuadrat), dan multivariat (uji Regresi Logistik). Hasil penelitian menunjukkan bahwa keluhan nyeri punggung derajat berat dialami oleh 48,9\% siswa. Hasil uji statistik, beberapa variabel yang berhubungan secara signifikan terhadap keluhan nyeri punggung antara lain jenis kelamin, IMT, berat tas, lama membawa tas, dan cara membawa tas. Hasil analisis multivariat, faktor dominan paling tinggi mempengaruhi keluhan nyeri punggung adalah cara membawa tas $(\mathrm{OR}=2,717)$. Saran penelitin ini memberikan pendidikan kesehatan terkait dengan tindakan penggunaan tas yang tepat, mengatur jadwal pembelajaran yang tepat, dan disediakan loker pribadi untuk setiap siswa.
\end{abstract}

Kata Kunci: Penggunaan Tas Sekolah, Nyeri Punggung, Remaja

\begin{abstract}
School hours and student extracurricular activities affect the load of the bags carried, so that students complain of back pain. The allowable load limit for backpacks is 10-15\% of body weight. This makes researchers interested in researching relationship between using school bags with back pain complaints to students at SMP Negeri 106 Jakarta. This type of research is descriptive with a cross sectional design. A sample of 305 students of SMP Negeri 106 Jakarta, selected by proportional random sampling. This research was conducted in April to September 2019. Data collection used questionnaires, and weighing bags. Data analysis was univariate, bivariate (Chi squared test), and multivariate (logistic regression test). The results showed that students who had complaints of severe back pain were 48.9\%. The results of the bivariate analysis showed that the variables had a significant relationship with back pain complaints were gender, BMI, weight of bags, length of carrying bags, and how to carry bags. The result of multivariate analysis showed that the dominant factor with the highest influence on back pain complaints was the way of carrying a bag $(O R=2,717)$. Suggestions are to provide health education related to the proper use of bags, set appropriate learning schedules, and provide personal lockers for each student.
\end{abstract}

Keywords: Use of School Bags, Back Pain 


\section{PENDAHULUAN}

Semakin berkembangnya dunia pendidikan saat ini, sehingga kondisi tersebut menuntut para siswa untuk aktif dalam pelaksanaan kegiatan belajar mengajar di sekolah. Jam pelajaran di sekolah yang bertambah dan juga didukung oleh kegiatan ekstrakurikuler yang diikuti oleh siswa, mempengaruhi terhadap beban tas yang seharihari dibawa oleh siswa ke sekolah. Padahal banyaknya beban yang dibawa tersebut, menimbulkan dampak negatif terhadap kesehatan siswa, salah satunya adalah adanya keluhan nyeri punggung yang dialami. Apabila kondisi itu dibiarkan, otomatis akan menjadi penyebab terjadinya cidera pada jaringan lunak, tulang, dan juga syaraf.

Berat tubuh sebagian besar ditopang oleh punggung bawah. Kondisi ini menimbulkan kerentanan terhadap kerusakan pada otot rangka dan ligamen punggung bawah. Biasanya rasa sakit yang timbul dan sering dialami akibat dari aktivitas fisik berat atau tidak biasa yang dilakukan adalah nyeri otot. Jika hal ini terjadi, dapat mengakibatkan beberapa titik tertentu pada otot terasa sangat sakit dan menghabkat gerakan seseorang. Hal ini sering ditemukan pada mereka yang sering melakukan kegiatan mengangkat beban berat memakai punggung. Diantaranya yaitu para siswa yang hampir seluruhnya menggunakan tas sekolah untuk membawa buku maupun barang lainnya ke sekolah (Suma'mur, 2007).

Nyeri punggung dapat didefinisikan sebagai nyeri yang bersifat lokal ataupun radikuler atau kedua-duanya yang dirasakan pada area sekitar thorak dan lumbal ataupun lumbo sakral. Hasil Survei yang dilakukan oleh Archives of Disease in Childhood terhadap 1.403 anak sekolah menemukan bahwa ada sebanyak $61,4 \%$ siswa mengalami nyeri pada punggung bagian bawah, dan kejadian tersebut Sebagian besar dialami oleh mereka yang berusia 12-17 tahun. Kondisi ini menggambarkan bahwa nyeri punggung bawah banyak dikeluhkan dan paling sering terjadi pada usia 12-17 tahun dimana merupakan waktu pertumbuhan cepat (rapid growth), selain itu juga karena banyaknya siswa menggendong tas ransel dengan beban berlebihan. Padahal anak-anak seharusnya tidak membawa beban lebih dari $10 \%$ dari berat tubuhnya (Rodríguez, 2012).

Penelitian Sari (2014) mengemukakan bahwa angka kejadian nyeri punggung pada anak usia 11 tahun mengalami peningkatan sebesar $12 \%$, dan mengalami peningkatan pada anak berusia 15 tahun sebesar 50\%. Dampak yang timbul dari terus meningkatnya angka kejadian nyeri punggung tersebut adalah menurunnya kualitas kesehatan anak serta pertumbuhan anak juga menjadi kurang optimal.

Menurut ACA (American Chiropratic Association), ketentuan terhadap nilai ambang batas beban tas punggung yang diperkenankan untuk dibawa oleh seseorang adalah maksimal 10-15\% dari berat badan. Disamping adanya berat beban tas, hal lain yang memberikan pengaruh adalah posisi bawah tas. Terlalu rendahnya tas ransel yang menggantung pada tubuh, mengakibatkan meningkatnya beban yang harus ditopang oleh bahu sehingga pada saat berjalan anak akan condong ke arah depan yang berakibat pada timbulnya otot yang mengalami ketegangan (ACA, 2011).

Berbagai penelitian terkait keluhan nyeri punggung antara lain penelitian Haidar (2015) di Tembalang, mengemukakan bahwa ada perbedaan keluhan nyeri punggung akibat pemakaian tas ransel pada murid kelas $\mathrm{V}$ pada SD X dan SD Y di Tembalang (nilai $\mathrm{p}=0,000$ ). Disamping itu, penelitian Ernawati (2016) di Madrasah Tsanawiyah Negeri 2 Pontianak juga menjelaskan bahwa sebanyak 141 orang $(74,2 \%)$ siswa yang mengalami nyeri punggung. Kaitannya dengan jenis kelamin, ternyata nyeri punggung lebih banyak ditemukan pada perempuan $(56,0 \%)$ dibandingkan laki-laki (44,0\%).

Siswa di SMP Negeri 106 Jakarta jumlahnya sebanyak 849 orang. Jam pelajaran di sekolah yaitu senin - jumat, dari pukul 06.30 - 14.30 WIB, kecuali hari Jumat jam sekolah hanya sampai pukul 12.30. Adanya kegiatan ekstrakurikuler yang wajib diikuti oleh siswa khususnya kelas 7 seperti Karate, Palang Merah Remaja (PMR), Paskibra, dan Silat, sehingga pada hari tertentu, para siswa pulang pada pukul 16.00 WIB.

Berdasarkan hasil observasi pendahuluan dengan melakukan wawancara terhadap beberapa orang siswa kelas 7 pada tanggal 21 Januari 2019, mereka menyatakan bahwa dengan adanya perbedaan sistem pembelajaran saat masih SD, yaitu terdapat penambahan jam pelajaran dan adanya ekstrakulikuler. Kondisi tersebut membuat mereka harus membawa buku dan barang lainnya lebih banyak, sehingga beban berat 
pada tas dirasakan pula pada bahu dan punggung mereka. Tujuan penelitian ini adalah untuk mengetahui hubungan penggunaan tas sekolah dengan keluhan nyeri punggung pada siswa di SMP Negeri 106 Jakarta tahun 2019.

\section{SUBYEK DAN METODE}

Penelitian ini adalah penelitian analitik menggunakan desain cross sectional (potong lintang) (Notoatmodjo, 2015). Tempat pelaksanaan penelitian adalah di SMP Negeri 106 Jakarta. Penelitian dilakukan pada bulan April-September 2019.

Populasi dalam penelitian ini yaitu seluruh murid di SMP Negeri 106 Jakarta yaitu 857 orang. Hasil penghitungan sampel sebanyak 305 orang. Untuk menentukan siswa yang diambil dari masing-masing kelas, maka digunakan metode simple random sampling dengan menggunakan perangkat lunak program SPSS.

Data yang digunakan dalam penelitian yaitu data primer. Metode pengumpulan data adalah melalui wawancara dengan menggunakan kuesioner dan penimbangan berat badan, berat tas, dan pengukuran tinggi badan. Analisis data yang digunakan yaitu univariat (distribusi frekuensi), bivariat (uji Kai Kuadrat), dan multivariat (Uji Regresi Logistik).

\section{HASIL}

Keluhan nyeri punggung dalam penelitian ini terdiri dari 8 pertanyaan, dikategorikan menurut nilai tengah. Cara menentukan nilai tengah menggunakan uji normalitas data yaitu uji skewness yang dibagi dengan standar error-nya.

Hasil uji normalitas data, didapatkan nilai skewness $(-0,475)$ yang dibagi dengan nilai SE-nya $(0,140)$ yaitu 3,37 , oleh sebab itu penentuan nilai tengah dengan menggunakan nilai median. Nilai median variabel keluhan nyeri punggung adalah 12 . Keluhan nyeri punggung dikategorikan menjadi berat, jika skor jawaban $<12$ dan kategori ringan, jika skor jawaban $\geq 12$. Secara jelas, hasil pengkategorian keluhan nyeri punggung pada siswa terlihat pada tabel 1 .
Tabel 1. Distribusi Frekuensi Keluhan Nyeri Punggung pada Siswacdi SMP Negeri 106 Jakarta Tahun 2019

\begin{tabular}{lcc}
\hline $\begin{array}{l}\text { Keluhan Nyeri } \\
\text { Punggung pada } \\
\text { Siswa }\end{array}$ & f & \% \\
\hline Berat & & \\
Ringan & 149 & 48,9 \\
\hline Total & 156 & 51,1 \\
\hline
\end{tabular}

Berdasarkan tabel 1 diketahui siswa yang mengalami keluhan nyeri punggung derajat ringan, yaitu sebanyak 156 orang $(51,1 \%)$, sedangkan yang mengalami keluhan derajat berat, yaitu sebanyak 149 orang $(48,9 \%)$.

Dalam penelitian ini, kategori umur responden, lama membawa tas, Indeks Berat Tas dilakukan berdasarkan nilai tengah (mean/median), karena belum ada standar baku penentuan umur dan lama membawa tas terkait keluhan nyeri punggung. Nilai tengah ditentukan menurut uji normalitas data menggunakan nilai skewness yang dibagi dengan nilai standar error-nya.

Hasil uji normalitas data umur, didapatkan nilai skewness $(0,475)$ dibagi nilai SE-nya $(0,140)$ yaitu sebesar 2,35 , sehingga penentuan nilai tengah dengan menggunakan nilai median. Nilai median variabel umur adalah 13 dibulatkan menjadi 13 tahun. Umur dikategorikan menjadi $\leq 13$ tahun dan $>13$ tahun. Hasil uji normalitas data lama membawa tas, diperoleh nilai skewness $(2,248)$ dibagi nilai standar error $(0,140)$ yaitu 16,057 , sehingga penentuan nilai tengah dengan menggunakan nilai median. Nilai median variabel lama membawa tas adalah 30 menit. Lama membawa tas dikategorikan menjadi < 30 menit dan $\geq 30$ menit. Hasil uji normalitas data indeks berat tas dan lama membawa tas, didapatkan angka skewness $(2,811)$ dibagi angka standar error $(0,140)$ yaitu 20,078 , dengan demikian penentuan nilai tengah menggunakan nilai median. Nilai median varabel indeks berat dan lama bawa tas adalah 110. Sehingga dikategorikan menjadi berisiko tinggi jika skor $\geq 110$ menit dan berisiko rendah jika skor < 110. 
Tabel 2. Distribusi Frekuensi Umur, Jenis Kelamin, Indeks Massa Tubuh (IMT), Berat Tas, Lama Membawa Tas, Cara Membawa Tas, Indeks Berat Tas dan Lama Membawa Tas pada Siswa di SMP Negeri 106 Jakarta Tahun 2019

\begin{tabular}{lccc}
\hline Variabel & Kategori & Frekuensi (n) & Persentase (\%) \\
\hline \multirow{2}{*}{ Umur } & $\leq 13$ tahun & 182 & 59,7 \\
& $>13$ tahun & 123 & 40,3 \\
\hline \multirow{2}{*}{ Jenis kelamin } & Laki-laki & 138 & 45,2 \\
& Perempuan & 167 & 54,8 \\
\hline \multirow{2}{*}{ Indeks massa tubuh } & Tidak normal & 178 & 58,4 \\
& Normal & 127 & 41,6 \\
\hline \multirow{2}{*}{ Berat tas } & Tidak normal & 79 & 25,9 \\
& Normal & 226 & 74,1 \\
\multirow{2}{*}{ Lama membawa tas } & $\geq 30$ menit & 183 & 60,0 \\
& $<30$ menit & 122 & 40,0 \\
\hline \multirow{2}{*}{ Cara membawa tas } & Kurang baik & 35 & 11,5 \\
& Baik & 270 & 88,3 \\
\hline Indeks berat dan lama & Berisiko tinggi & 155 & 50,8 \\
membawa tas & Berisiko rendah & 150 & 49,2 \\
\hline
\end{tabular}

Berdasarkan tabel 2, menemukan bahwa sebagian besar siswa berumur $\leq 13$ tahun $(59,7 \%)$, berjenis kelamin perempuan $(54,8 \%)$, memiliki indeks massa tubuh tidak normal $(58,4 \%)$, berat tas normal $(74,1 \%)$, lama membawa tas $\geq 30$ menit $(60,0 \%)$, cara membawa tas baik $(88,3 \%)$, dan indeks berat dan lama membawa tas termasuk berisiko tinggi $(50,8 \%)$. Hasil analisis bivariat antara umur, jenis kelamin, indeks massa tubuh (IMT), berat tas, lama membawa tas, cara membawa tas, indeks berat tas dan lama membawa tas dengan keluhan nyeri punggung pada siswa memakai uji Kai Kuadrat, secara jelas terlihat pada tabel 3 .

Tabel 3. Hasil Analisis Bivariat Hubungan Antara Umur, Jenis Kelamin, Indeks Massa Tubuh (IMT), Berat Tas, Lama Membawa Tas, Cara Membawa Tas, Indeks Berat Tas dan

Lama Membawa Tas dengan Keluhan Nyeri Punggung pada Siswa di SMP Negeri 106 Jakarta Tahun 2019

\begin{tabular}{|c|c|c|c|c|c|c|}
\hline \multirow[t]{2}{*}{ No } & \multirow[t]{2}{*}{ Variabel } & \multicolumn{2}{|c|}{$\begin{array}{l}\text { Keluhan Nyeri } \\
\text { Punggung }\end{array}$} & \multirow[t]{2}{*}{ Total } & \multirow[t]{2}{*}{ Nilai $p$} & \multirow[t]{2}{*}{$\begin{array}{c}\text { POR } \\
(95 \% \mathrm{CI})\end{array}$} \\
\hline & & Berat & Ringan & & & \\
\hline 1 & $\begin{array}{l}\text { Umur } \\
\leq 13 \text { tahun } \\
>13 \text { tahun }\end{array}$ & $\begin{array}{c}83 \\
(45,6 \%) \\
66 \\
(53,7 \%) \\
\end{array}$ & $\begin{array}{c}99 \\
(54,4 \%) \\
57 \\
(46,3 \%) \\
\end{array}$ & $\begin{array}{c}182 \\
(100 \%) \\
123 \\
(100 \%) \\
\end{array}$ & 0,206 & $\begin{array}{c}0,724 \\
(0,458-1,146)\end{array}$ \\
\hline 2 & $\begin{array}{l}\text { Jenis kelamin } \\
\text { Laki-laki } \\
\text { Perempuan }\end{array}$ & $\begin{array}{c}57 \\
(41,3 \%) \\
92 \\
(55,1 \%) \\
\end{array}$ & $\begin{array}{c}81 \\
(58,7 \%) \\
75 \\
(44,9 \%) \\
\end{array}$ & $\begin{array}{c}138 \\
(100 \%) \\
167 \\
(100 \%) \\
\end{array}$ & 0,022 & $\begin{array}{c}0,574 \\
(0,364-0,905)\end{array}$ \\
\hline
\end{tabular}




\begin{tabular}{|c|c|c|c|c|c|c|}
\hline \multirow[t]{2}{*}{ No } & \multirow[t]{2}{*}{ Variabel } & \multicolumn{2}{|c|}{$\begin{array}{c}\text { Keluhan Nyeri } \\
\text { Punggung }\end{array}$} & \multirow[t]{2}{*}{ Total } & \multirow[t]{2}{*}{ Nilai $p$} & \multirow[t]{2}{*}{$\begin{array}{c}\text { POR } \\
(95 \% \mathrm{CI})\end{array}$} \\
\hline & & Berat & Ringan & & & \\
\hline \multirow[t]{3}{*}{3} & $\begin{array}{l}\text { Indeks Massa } \\
\text { Tubuh }\end{array}$ & & & & & \\
\hline & Tidak normal & $\begin{array}{c}97 \\
(54,5 \%)\end{array}$ & $\begin{array}{c}81 \\
(45,5 \%)\end{array}$ & $\begin{array}{c}178 \\
(100 \%)\end{array}$ & \multirow[b]{2}{*}{0,027} & \multirow{2}{*}{$\begin{array}{c}1,727 \\
(1,090-2,738)\end{array}$} \\
\hline & Normal & $\begin{array}{c}52 \\
(40,9 \%) \\
\end{array}$ & $\begin{array}{c}75 \\
(59,1 \%) \\
\end{array}$ & $\begin{array}{c}127 \\
(100 \%)\end{array}$ & & \\
\hline \multirow[t]{3}{*}{4} & Berat Tas & & & & & \\
\hline & Tidak normal & $\begin{array}{c}48 \\
(60,8 \%)\end{array}$ & $\begin{array}{c}31 \\
(392 \%)\end{array}$ & $\begin{array}{c}79 \\
(100 \%)\end{array}$ & \multirow[b]{2}{*}{0,020} & \multirow{2}{*}{$\begin{array}{c}1,916 \\
(1,137-3,230)\end{array}$} \\
\hline & Normal & $\begin{array}{c}101 \\
(44,7 \%)\end{array}$ & $\begin{array}{c}125 \\
(55,3 \%)\end{array}$ & $\begin{array}{c}226 \\
(100 \%)\end{array}$ & & \\
\hline \multirow[t]{3}{*}{5} & $\begin{array}{l}\text { Lama } \\
\text { Membawa } \\
\text { Tas }\end{array}$ & & & & & \multirow{3}{*}{$\begin{array}{c}2,253 \\
(1,408-3,604)\end{array}$} \\
\hline & & $\begin{array}{c}104 \\
(56,8 \%)\end{array}$ & $\begin{array}{c}79 \\
(43,2 \%)\end{array}$ & $\begin{array}{c}183 \\
(100 \%)\end{array}$ & \multirow{2}{*}{0,001} & \\
\hline & $<30$ menit & $\begin{array}{c}45 \\
(36,9 \%) \\
\end{array}$ & $\begin{array}{c}77 \\
(63,1 \%) \\
\end{array}$ & $\begin{array}{c}122 \\
(100 \%)\end{array}$ & & \\
\hline \multirow[t]{3}{*}{6} & $\begin{array}{l}\text { Cara } \\
\text { Membawa } \\
\text { Tas }\end{array}$ & & & & & \multirow{3}{*}{$\begin{array}{c}2,531 \\
(1,192-5,372)\end{array}$} \\
\hline & Kurang baik & $\begin{array}{c}24 \\
(68,6 \%)\end{array}$ & $\begin{array}{c}11 \\
(31,4 \%)\end{array}$ & $\begin{array}{c}35 \\
(100 \%)\end{array}$ & \multirow{2}{*}{0,021} & \\
\hline & Baik & $\begin{array}{c}125 \\
(46,3 \%) \\
\end{array}$ & $\begin{array}{c}145 \\
(53,7 \%) \\
\end{array}$ & $\begin{array}{c}270 \\
(100 \%) \\
\end{array}$ & & \\
\hline \multirow[t]{3}{*}{7} & $\begin{array}{l}\text { Indeks Berat } \\
\text { dan Lama } \\
\text { Bawa Tas }\end{array}$ & & & & & \\
\hline & Berisiko tinggi & $\begin{array}{c}85 \\
(54,8 \%)\end{array}$ & $\begin{array}{c}70 \\
(45,2 \%)\end{array}$ & $\begin{array}{c}155 \\
(100 \%)\end{array}$ & \multirow{2}{*}{0,044} & \multirow{2}{*}{$\begin{array}{c}1,632 \\
(1,038-2,565)\end{array}$} \\
\hline & $\begin{array}{l}\text { Berisiko } \\
\text { rendah }\end{array}$ & $\begin{array}{c}64 \\
(42,7 \%)\end{array}$ & $\begin{array}{c}86 \\
(57,3 \%)\end{array}$ & $\begin{array}{c}150 \\
(100 \%)\end{array}$ & & \\
\hline
\end{tabular}

Berdasarkan tabel 3, diketahui proporsi keluhan nyeri punggung berat, lebih banyak ditemukan pada responden yang berumur $>13$ tahun $(53,7 \%)$, jenis kelamin perempuan $(55,1 \%)$, IMT tidak normal $(54,5 \%)$, berat tas tidak normal $(60,8 \%)$, lama membawa tas $\geq 30$ menit $(56,8 \%)$, cara membawa tas kurang baik $(68,6 \%)$, indeks berat dan lama bawa tas berisiko tinggi $(54,8 \%)$.

Variabel yang mempunyai hubungan signifikan dengan keluhan nyeri punggung yaitu jenis kelamin $(\mathrm{p}=0,022$ dan $\mathrm{OR}=0,574)$, IMT $(\mathrm{p}=0,027$ dan OR $=1,727)$, berat tas $(\mathrm{p}$ $=0,020$ dan $\mathrm{OR}=1,916)$, lama membawa tas ( $\mathrm{p}$ $=0,001$ dan $\mathrm{OR}=2,253)$, cara membawa tas ( $\mathrm{p}$ $=0,021$ dan $\mathrm{OR}=2,531)$ dan indeks berat dan lama bawa tas $(\mathrm{p}=0,044$ dan $\mathrm{OR}=1,632)$. Variabel yang tidak memiliki hubungan signifikan dengan keluhan nyeri punggung yaitu variabel umur $(\mathrm{p}=0,206)$.

Analisis multivariat bertujuan mendapatkan suatu model terbaik dalam melihat hubungan umur, jenis kelamin, IMT, berat tas, lama membawa tas, dan cara membawa tas dengan keluhan nyeri punggung pada siswa. Dalam pemodelan ini semua variabel kandidat diujicobakan membentuk model persamaan. Model terbaik dipilih melalui pertimbangan terhadap berbagai aspek penilaian yang telah ditentukan, yaitu nilai signifikan ratio log-likehood ( $\mathrm{p}<0,05$ ), persen klasifikasi benar yang relatif besar, angka 
signifikan $\mathrm{p}=$ wald $(\mathrm{p}<0,05)$, nilai $\mathrm{OR}$ dan juga stabilitas nilai 95\% OR. Model dipilih dengan menggunakan metode Enter dengan memasukkan kemungkinan bentuk variasi model dan tidak menyerahkan sepenuhnya pada analisis yang dilakukan komputer (Hastono, 2012). Hasil akhir analisis multivariat ternyata hanya empat variabel independen yang lolos. Hasilnya dapat dilihat dalam tabel 4.

\section{Tabel 4. Hasil Akhir Analisis Regresi Logistik antara Variabel Jenis Kelamin, Indeks Massa Tubuh, Lama Membawa Tas dan Cara Membawa Tas}

\begin{tabular}{cccc}
\hline Variabel & $\mathbf{P}$ & OR & CI.95\% \\
\hline Jenis kelamin & 0,003 & 0,476 & $0,292-$ \\
Indeks Massa & & & 0,777 \\
Tubuh & 0,015 & 1,833 & $1,127-$ \\
Lama & & & 2,982 \\
Membawa Tas & 0,000 & 2,561 & $1.554-$ \\
$\quad$ Cara & 0,012 & 2,717 & $1.241-$ \\
Membawa Tas & 0,950 \\
\hline
\end{tabular}

Hasil akhir analisis multivariat, menemukan bahwa terdapat 4 variabel memiliki nilai $\mathrm{p}<0,05$, yaitu jenis kelamin, indeks massa tubuh, lama membawa tas, dan cara membawa tas, sehingga dapat disimpulkan variabel jenis kelamin, indeks massa tubuh, lama membawa tas, dan cara membawa tas berhubungan secara signifikan dengan keluhan nyeri punggung, dan tidak ada yang menjadi variabel confounding karena dalam analisis multivariat tidak ada variabel yang mengalami perubahan $\mathrm{OR}>10 \%$. Ditemukan faktor dominan tertinggi yaitu cara membawa tas (OR $=2,717$ ) berhubungan dengan keluhan nyeri punggung, artinya siswa yang cara membawa tasnya kurang baik akan berisiko 2,7 kali lebih berat merasakan keluhan nyeri punggung dibandingkan dengan siswa yang cara membawa tasnya baik setelah dikontrol variabel lama membawa tas, indeks massa tubuh, dan jenis kelamin.

\section{DISKUSI}

Berdasarkan hasil penelitian mengemukakan bahwa siswa yang merasakan keluhan nyeri punggung derajat ringan, yaitu sebesar $51,1 \%$, sedangkan yang mengalami keluhan derajat berat, sebanyak 48,9\%. Menurut teori yang dijelaskan oleh Tarwaka (2008) mengemukakan bahwaPemberian beban yang dilakukan secara terus menerus dan dalam posisi yang statis dapat menjadi penyebab timbulnya gangguan pada aliran darah saat mengangkut oksigen, dan lama kelamaan akan terakumulasi menjadi kekurangan oksigen pada otot, sehingga timbul metabolisme anaerobik, pada akhirnya asam laktat dan panas tubuh akan mengalami penimbunan, dan akhirnya berdampak pada terjadinya kelelahan pada otot skeletal yang dialami berupa keluhan nyeri otot.

Hasil penelitian ini juga diperkuat oleh penelitian Ernawati (2016) di Sekolah Madrasah Tsanawiyah Negeri 2 Pontianak dimana dalam penelitiannya diperoleh informasi bahwa murid yang mengalami nyeri punggung lebih dari separuhnya, yaitu sebanyak $74,2 \%$. Adanya kesamaan hasil penelitian ini antara teori dan penelitian lain, menggambarkan bahwa beban tas yang dibawa oleh siswa dalam waktu yang berulang-ulang dan dalam posisi statis, otomatis akan berdampak pada kelelahan otot skeletal. Hal ini dipengaruhi oleh banyak faktor seperti berat beban tas yang dibawa siswa, lama membawa tas setiap harinya, cara membawa tas, maupun faktor lainnya. Padahal keluhan nyeri punggung yang dialami oleh siswa tersebut, apalagi yang sifatnya permanen/jangka panjang, dapat berpengaruh terhadap kesehatan siswa dan juga konsentrasi belajar yang dialami.

Berdasarkan hasil penelitian terkait umur, sebagian besar siswa berumur $\leq 13$ tahun $(59,7 \%)$. Hasil analisis hubungan umur dengan keluhan nyeri punggung pada siswa, diperoleh nilai $p=0,206$ artinya $\mathrm{p}>$ alpha $(0,05)$, dengan demikian disimpulkan bahwa tidak ada hubungan yang signifikan antara umur dengan keluhan nyeri punggung pada siswa. Dari hasil penelitian, ternyata umur tidak berhubungan secara signifikan dengan keluhan nyeri punggung yang dialami siswa. Hasil penelitian Dumondor (2015) juga mengemukakan bahwa tidak terdapat hubungan yang bermakna antara umur dengan nyeri punggung pada siswa di SMP Negeri 2 Tombatu. Dalam penelitiannya menjelaskan bahwa nyeri punggung dialami oleh semua kelompok umur dengan total $83,3 \%$. Hal tersebut juga ditemukan dalam penelitian ini, karena keluhan nyeri punggung dialami oleh sebagian besar siswa dengan umur yang hampir merata, yaitu berkisar 45,6\% untuk umur $\leq 13$ tahun dan 53,7\% untuk umur $>13$ tahun. Namun demikian, tidak adanya hubungan yang bermakna antara umur dengan keluhan nyeri punggung dalam penelitian ini, 
dapat disebabkan oleh adanya faktor lain yang pengaruhnya lebih besar, seperti Indeks Massa Tubuh (IMT), berat tas, lama membawa tas, cara membawa tas, dan sebagainya.

Berdasarkan hasil penelitian mengenai jenis kelamin diketahui sebagian besar siswa perempuan $(54,8 \%)$. Hasil analisis bivariat membuktikan ada hubungan yang bermakna antara jenis kelamin dengan keluhan nyeri punggung pada siswa $(\mathrm{p}=0,022$ dan $\mathrm{OR}=$ 0,574 ). Dalam penelitian ini, ternyata nilai $O R$ yang diperoleh adalah $<1$, artinya sebagai faktor pencegah. Dalam arti lain, perempuan memiliki risiko lebih tinggi untuk mengalami keluhan nyeri punggung dibandingkan lakilaki. Menurut teori, tingkat risiko keluhan otot dipengaruhi salah satunya oleh jenis kelamin. Kondisi tersebut dapat terjadi karena secara fisiologis, kemampuan otot laki-laki cenderung lebih besar bila dibandingkan dengan kemampuan otot pada perempuan.

Hasil penelitian ini sejalan dengan penelitian Ernawati (2016) di Sekolah Madrasah Tsanawiyah Negeri 2 Pontianak mengemukakan adanya hubungan antara jenis kelamin dengan kejadian nyeri punggung pada murid kelas IX (nilai $\mathrm{p}=0,005$ ). Proporsi murid perempuan yang merasakan nyeri punggung, lebih banyak $(56,0 \%)$ bila dibandingkan dengan murid laki-laki (44,0\%), karena terkait dengan kemampuan otot perempuan yang lebih rendah daripada laki-laki.

Selain itu berdasarkan hasil penelitian Dumondor (2015) juga menemukan bahwa karakteristik responden perempuan yang mengalami nyeri punggung sebesar $46,7 \%$, lebih banyak dibandingkan nyeri punggung yang dialami pada laki-laki $(36,7 \%)$.

Kemampuan fisik perempuan secara fisiologis lebih rendah dibandingkan laki-laki. Oleh sebab itu, laki-laki cenderung mengalami keluhan nyeri punggung dengan derajat ringan dibandingkan dengan siswa perempuan.

Hasil penelitian mengenai indeks massa tubuh (IMT) diketahui siswa yang memiliki IMT normal, yaitu sebanyak 127 orang $(41,6 \%)$. Hasil analisis bivariat membuktikan ada hubungan IMT dengan keluhan nyeri punggung pada siswa $(\mathrm{p}=0,027$ dan OR $=$ 1,727).

Hasil penelitian ini mengemukakan bahwa siswa dengan IMT tidak normal, berisiko lebih besar untuk mengalami nyeri punggung. Hal ini sesuai dengan teori yang dikemukakan oleh Roland, Roy, Marc,
Buckwalter Goldber, Victor (2010) yang dikutip Lailani (2013) menjelaskan bahwa meningkatnya IMT seseorang dapat menjadi penyebab melemahnya tonus otot abdomen. Hal ini mengakibatkan pusat gravitasi akan terdorong ke depan tubuh dan menyebabkan bertambahnya lordosis lumbalis, yang kemudian akan timbul kelelahan pada otot paravertebra. Pada saat semakin bertambahnya berat badan, maka akan terjadi penekanan pada tulang belakang akibat dari penerimaan beban yang berat tersebut, yang dapat berdampak pada timbulnya stress mekanis pada bagian bawah.

Selain itu, hasil penelitian (Ernawati, 2016) juga mengemukakan bahwa sebagian besar siswa memiliki status gizi normal, yaitu sebanyak 171 orang $(90,0 \%)$. Status gizi anak juga menjadi salah satu faktor risiko timbulnya nyeri punggung. Pada anak dengan status gizinya yang berlebih atau kegemukan menjadi penyebab kejadian nyeri punggung.

Hasil penelitian mengenai berat tas, diketahui sebagian besar siswa berat tasnya normal, yaitu sebanyak 226 orang $(74,1 \%)$.). Hasil analisis bivariat menunjukkan adanya hubungan yang signifikan antara berat tas dengan keluhan nyeri punggung pada siswa ( $\mathrm{p}$ $=0,020$ dan $\mathrm{OR}=1,916$ )

Ketentuan ACA (American Chiropratic Association), terhadap nilai ambang batas beban tas punggung yang diperkenankan untuk dibawa oleh seseorang adalah paling banyak 10-15\% dari berat badannya. Pendapat Fageeh A (2013) yang melakukan penelitian mengenai hubungan berat tas anak sekolah dengan kapasitas vital paru-paru, potensi nyeri punggung, dan masalah postur, mengemukakan bahwa ketika siswa datang ke sekolah membawa beban berlebihan, maka kapasitas vital paru-paru akan menurun, gerak dari flexi dan ekstensi juga cenderung menurun, sehingga dapat menimbulkan pembungkukan ke kiri maupun kanan.

Selain itu, penelitian Alghamdi et al., (2018) di Kota Dammam Kerajaan Saudi Arabia, menemukan bahwa ada hubungan yang bermakna antara berat tas dengan keluhan nyeri punggung pada siswa SMP $(\mathrm{p}=0,042)$. Penelitian (Hendri, 2014) juga mengemukakan bahwa dari hasil uji statistik Fisher menunjukkan adanya hubungan yang bermakna antara beban backpack (carry less) terhadap kejadian low back pain pada mahasiswa di Universitas Riau (nilai $\mathrm{p}=0,000$ ). Proporsi 
mahasiswa yang bebannya tidak sesuai, seluruhnya $(100 \%)$ mengalami kejadian low back pain.

Dalam penelitian ini, proporsi keluhan nyeri punggung pada siswa yang berat tasnya tidak sesuai adalah sebesar $60,8 \%$, lebih rendah dibandingkan dengan proporsi low back pain pada penelitian Hendri (2014) tersebut. Hal tersebut dapat terjadi karena adanya perbedaan umur responden pada kedua penelitian tersebut, dimana penelitian Hendri (2014) dengan responden mahasiswa sedangkan penelitian ini respondennya adalah siswa SMP, yang otomatis akan berbeda pula pada proporsinya. Karena kekuatan otot juga dipengaruhi oleh umur, apalagi didukung oleh lamanya membawa

Berdasarkan hasil penelitian tentang lama membawa tas pada penelitian ini, diketahui sebagian besar siswa lama membawa tas $\geq 30$ menit, sebanyak 183 orang $(60,0 \%)$. Hasil uji statistik menemukan ada hubungan yang signifikan antara lama membawa tas dengan keluhan nyeri punggung pada siswa ( $\mathrm{p}$ $=0,001$ dan $\mathrm{OR}=2,253$ ).

Menurut Alaa'Osaid (2012) dalam Fathoni (2013), penelitian yang dilakukan di Turki terhadap 800 orang siswa sekolah menunjukkan bahwa lamanya memakai tas yaitu sekitar 5-30 menit sejak dari rumah sampai ke sekolah yang dilakukan rutin tiap hari dengan berat tas rata-rata adalah $5,267 \mathrm{~kg}$ atau $12,3 \%$ dari berat badan, dapat menjadi penyebab timbulnya keluhan nyeri bahu $47,8 \%$, nyeri punggung bagian bawah $21,6 \%$ dan nyeri leher sebesar $18,2 \%$.

Penelitian Ernawati (2016) pada Siswa Kelas IX Madrasah Tsanawiyah Negeri 2 Pontianak juga menemukan bahwa ada hubungan yang bermakna lama menggunakan tas > 30 menit setiap hari $(p=0,018)$ terhadap kejadian nyeri punggung.

Hal tersebut menggambarkan bahwa lama penggunaan tas memang menjadi salah satu faktor risiko yang dapat menyebabkan keluhan nyeri punggung. Meskipun dalam penelitian Ernawati (2016) tidak menjelaskan terkait berapa besar faktor risikonya tersebut. Namun sudah cukup menggambarkan adanya hubungan yang signifikan, dan dilengkapi dari hasil penelitian ini yang menjelaskan juga besarnya risiko tersebut yaitu 2,253 kali.

Terkait dengan hasil penelitian tentang cara membawa tas pada responden, diketahui sebagian besar siswa cara membawa tasnya baik, yaitu 270 orang $(88,3 \%)$. Hasil analisis bivariat membuktikan ada hubungan yang signifikan antara cara membawa tas dengan keluhan nyeri punggung pada siswa $(\mathrm{p}=0,021$ dan $\mathrm{OR}=2,531$ ).

Menurut standar American Chiropractic Association (ACA, 2011) menjelaskan bahwa cara bawa tas secara tepat dan benar yaitu dengan memakai kedua bahu supaya tidak terjadi pemusatan tumpuan beban lebih pada salah satu sisi bahu saja. Selain itu, agar beban dapat tersebar secara merata pada anggota tubuh yang lainnya, karena tulang punggung cenderng akan lebih condong ke arah yang berlawanan dengan sisi yang menopang beban tersebut.

Penelitian yang dilakukan Haidar 2015) mengemukakan bahwa dari hasil penelitiannya tersebut diketahui sebagian besar responden kelas V SD X dan SD Y sudah membawa tas dengan cara yang benar dengan proporsi yaitu $96,7 \%$ pada siswa SD X dan $98,0 \%$ pada siswa SD Y.

Penelitian yang juga dilaksanakan pada SD Karachi di Pakistan menemukan ada hubungan yang bermakna antara posisi tubuh saat membawa tas dengan kejadian muskuloskeletal (nilai $\mathrm{p}=0,001$ ). Jika beban kerja tulang belakang terlampau berat maka dapat menjadi penyebab timbulnya berbagai macam kelainan pada tulang belakang misalnya kelainan postur tubuh (Zaidi, 2016). Disamping itu, penelitian (Hendri, 2014) juga diketahui bahwa mahasiswa yang tidak sesuai dalam melakukan keseimbangan pada penggunaan backpack (balance), seluruhnya (100,0\%) mengalami kejadian low back pain. Hasil analisis bivariat Chi-Square menunjukkan adanya hubungan yang bermakna antara keseimbangan saat menggunakan backpack (balance) dengan kejadian low back pain pada mahasiswa Universitas Riau (nilai $\mathrm{p}$ $=0,000$ ).

Hasil penelitian mengenai indeks berat dan lama membawa tas menunjukkan bahwa siswa yang indeks berat dan lama bawa tas termasuk berisiko tinggi, yaitu sebanyak $50,8 \%$. Sampai sejauh ini belum ditemukan adanya penelitian mengenai perpaduan/ penggabungan antara berat tas dan lama membawa tas sehingga menjadi suatu indeks. Oleh sebab itu, peneliti mencoba menggabungkan kedua variabel tersebut untuk di analisis ada tidaknya asosiasi/hubungan antara indeks tersebut dengan keluhan nyeri 
punggung. Hasil analisis hubungan indeks berat dan lama membawa tas dengan keluhan nyeri punggung pada siswa diperoleh nilai $\mathrm{p}=0,044$ dan $\mathrm{OR}=1,632$, sehingga ada hubungan yang bermakna antara indeks berat dan lama membawa tas dengan keluhan nyeri punggung pada siswa.

Penelitian Farhood (2013) di Kota Hilla Babylon Irak, menemukan bahwa berat tas berhubungan signifikan dengan keluhan nyeri punggung $(\mathrm{p}=0,001)$. Dalam penelitiannya tersebut, kategori berat tas adalah $<5 \mathrm{~kg}$ dan $\geq$ $5 \mathrm{~kg}$. Kondisi tersebut menggambarkan bahwa berat tas sangat penting peranannya terhadap keluhan yang dirasakan oleh siswa.

Terkait lama membawa tas, penelitian Haselgrove (2008) di Australia mengemukakan bahwa lama membawa tas berhubungan secara signifikan dengan keluhan nyeri punggung $(\mathrm{p}=$ 0,010), semakin lama membawa tas, akan semakin merasakan keluhan nyeri punggung.

Dari kedua penelitian tersebut, dapat kita pahami bahwa berat tas dan lama membawa tas memiliki keeratan hubungan, yang dibuktikan dengan hasil penelitian saat ini, ternyata indeks berat dan lama membawa tas memang memiliki hubungan yang signifikan dengan keluhan nyeri punggung yang dirasakan.

Hasil analisis multivariat, faktor dominan paling tinggi adalah cara membawa tas $(\mathrm{OR}=2,717)$ berhubungan dengan keluhan nyeri punggung, artinya siswa yang cara membawa tasnya kurang baik akan berisiko 2,7 kali lebih berat mengalami keluhan nyeri punggung dibandingkan dengan siswa yang cara membawa tasnya baik setelah dikontrol variabel lama membawa tas, IMT, dan jenis kelamin.

Menurut Trevelyan (2003) yang dikutip oleh (Fathoni, 2013), mengemukakan bahwa cara memakai tas punggng yang dilakukan secara rutin, posisi yang tidak baik dan juga terlampau berat akan menjadi penyebab timbulnya perubahan kinematik, fisiologis, dan histologis maupun keluhan nyeri punggung. Beberapa penelitian menunjukkan bahwa terdapat kecenderungan nyeri punggung yang meningkat pada murid sekolah dan sebagian dari penelitian tersebut mengemukakan bahwa pemakaian tas punggung yang tidak tepat berpengaruh terhadap kejadian trauma musculoskeletal (Legiran, 2012).

Hasil penelitian Lisanti (2017) juga mengemukakan bahwa dari hasil uji statistik chi square didapatkah nilai $\mathrm{p}=0,006(\mathrm{p} \leq 0,05)$, hal ini menunjukkan ada hubungan yang bermakna antara cara bawa tas dengan keluhan muskuloskeletal pada murid MI Nashrul Fajar Kecamatan Tembalang Kota Semarang.

Anak yang membawa tas dengan hanya memakai satu tali, memiliki risiko 2 kali lipat akan mengalami perubahan postur dibandingkan dengan anak yang memakai dua tali pada tas ransel (Ernawati, 2016). Hal tersebut menggambarkan bahwa cara membawa tas memang merupakan faktor penting yang harus diperhatikan oleh siswa, karena pengaruhnya lebih dominan dibandingkan faktor lainnya.

\section{KESIMPULAN}

Dari hasil penelitian, diketahui sebagian besar siswa mengalami keluhan nyeri punggung derajat ringan $(51,1 \%)$, siswa berumur $\leq 13$ tahun, berjenis kelamin perempuan, memiliki IMT tidak normal, berat tas normal, lama membawa tas $\geq 30$ menit, cara membawa tas baik, dan indeks berat dan lama bawa tas termasuk berisiko tinggi. Ada hubungan bermakna antara jenis kelamin, IMT, berat tas, lama membawa tas, cara membawa tas, dan indeks berat dan lama bawa tas dengan keluhan nyeri punggung pada siswa SMP. Variabel yang tidak berhubungan secara bermakna adalah umur. Faktor paling dominan yang mempengaruhi keluhan nyeri punggung adalah cara membawa tas $(\mathrm{OR}=2,717)$.

Rekomendasi yang dapat diberikan dari hasil penelitian ini antara lain adalah menjadi masukan bagi pihak sekolah agar dapat memberikan pendidikan kesehatan melalui kerjasama dengan institusi kesehatan, upayakan untuk mengatur jadwal pembelajaran yang tepat, agar beban tas yang dibawa oleh siswa menjadi tidak berlebihan. Selain itu, sebaiknya disediakan loker pribadi untuk setiap siswa, dan pihak sekolah agar dapat memantau siswa dalam penggunaan tas ke sekolah, baik dari segi berat tas, lama penggunaan, dan cara pemakaian tas

\section{UCAPAN TERIMAKASIH}

Kami ucapkan terimakasih kepada KEMENKES yang telah memberikan dana Riset Pembinaan Tenaga Kesehatan (RISBINAKES) Tahun 2019 untuk kegiatan penelitian ini. Kemudian kepada Direktur Poltekkes Kemenkes Jakarta III beserta jajarannya. Kapuslitmas PKJ III, Tim Pakar Dr. drg. Wasis Sumartono, Sp.KG dan Dr. Titi 
Sulastri, S.Kp. M.Kes. yang telah memberikan saran dan masukannya. Tidak lupa ucapan terimakasih juga kepada Ibu Ratu Karel Lina, SST.Ft., SKM, MPH., selaku Kajur Fisioterapi, beserta jajaran manajemen dan seluruh dosen di Jurusan Fisioterapi yang telah banyak mendukung.

\section{DAFTAR PUSTAKA}

ACA. (2011). Backpack Misuse Leads To Chronic Back Pain, Doctors of Chiropractic Say. http://www.acatoday.org/content _css.cfm?CID $=65$

Alghamdi et al. (2018). A study of school bag weight and back pain among intermediate female students in Dammam City, Kingdom of Saudi Arabia. Journal of Nursing Education and Practice, 8 Nomor. 1.

Dumondor, S. V. (2015). Hubungan Penggunaan Ransel Dengan Nyeri Punggung Dan Kelainan Bentuk Tulang Belakang Pada Siswa Di SMP Negeri 2 Tombatu. Jurnal E-Clinic (ECl), Vol. 3 nomor 1.

Ernawati, T. (2016). Hubungan Penggunaan Tas Ransel terhadap Kejadian Nyeri Punggung Bawah pada Siswa Kelas IX Madrasah Tsanawiyah Negeri 2 Pontianak. Jurnal Cerebellum. FK UNTAN, Vol. 2 Nomor. 2.

Fageeh A, A. (2013). The effect of school bag weight on pain, posture, and vital capacity of lung of three elementary of elementary school in Bethlehem district on Palestine. Middle East Journal of Family Medicine, Vol. 7.

Farhood, H. (2013). Low back pain in schoolchildren: the role of school bag weight and carrying way. Journal of Natural Sciences Research www.Iiste.Org, Vol. 3 No. 8.

Fathoni, F. D. (2013). Hubungan Pemakaian Backpack Dengan Terjadinya Nyeri Muskuloskeletal Pada Anak Usia 8 - 12 Tahun Di SDN 2 Bener Sragen.

Haidar. (2015). Perbedaan Keluhan Nyeri Punggung Pada Siswa Kelas V Antara SD X dan SD Y Akibat Penggunaan Tas Punggung Di Tembalang. Jurnal Kesehatan Masyarakat (e Journal), Vol. 3 Nomor 3.
Haselgrove. (2008). Perceived school bag load, duration of carriage, and method of transport to school are associated with spinal pain in adolescents: an observational study. Curtin University of Technology. Australian Journal of Physiotherapy, Vol. 54.

Hastono, S. (2012). Analisis Data. Fakultas Kesehatan Masyarakat Universitas Indonesia.

Hendri. (2014). Hubungan Penggunaan Backpack Dengan Kejadian Low Back Pain Pada Mahasiswa Universitas Riau. Jurnal JOM PSIK Universitas Riau, Vol. 1 Nomor 2.

Lailani, T. M. (2013). Hubungan antara peningkatan indeks massa tubuh dengan kejadian nyeri punggung bawah pada pasien rawat jalan di poliklinik saraf RSUD Dokter Soedarso Pontianak. Jurnal Untan.

Legiran. (2012). Berat Tas Punggung Dan Prevalensi Nyeri Punggung Pada Siswa Sekolah Dasar di Palembang. Univesitas Sriwijaya Palembang.

Lisanti. (2017). Hubungan Penggunaan Tas Punggung Dengan Keluhan Muskuloskeletal Pada Siswa Mi Nashrul Fajar Meteseh Kecamatan Tembalang Kota Semarang. Jurnal Kesehatan Masyarakat (e-Journal), Vol. 5 Nomor 4.

Notoatmodjo, S. (2015). Metodologi Penelitian Kesehatan. Penerbit Rineka Cipta.

Rodríguez. (2012). School children's backpacks, back pain and back pathologies. Arch Dis Child, Vol. 97, 730-732.

Sari, R. A. (2014). Analisis penggunaan bangku sekolah ukuran fixed dan adjustable untuk anak sekolah dasar. Jemis, Vol. 2 Nomor 1.

Suma'mur. (2007). Keselamatan Kerja dan Pencegahan Kecelakaan. CV. Haji Masagung.

Tarwaka. (2008). Keselamatan Dan Kesehatan Kerja "Manajemen Dan Implementasi K3 Di Tempat Kerja." Harapan Press.

Zaidi. (2016). International Conference on Statistical Sciences. Association Of Musculoskeletalpain With Heavy Bag Packs Among School Children, 29-38. 